\title{
Participation in Organized Leisure Activities as a Context for the Development of Social Competence among Preschool Children
}

\author{
François Poulin ${ }^{1}$, Frédéric McGovern-Murphy ${ }^{1}$, Alessandra Chan $^{1} \&$ France Capuano ${ }^{1}$ \\ ${ }^{1}$ Department of Psychology, Université du Québec à Montréal, Montréal, Canada \\ Correspondence: François Poulin, Department of Psychology, Université du Québec à Montréal, UQAM, Case \\ postale 8888, Succursale Centre-ville, H3C 3P8, Montréal, Canada. E-mail: poulin.francois@uqam.ca
}

Received: May 3, 2012

Accepted: May 25, $2012 \quad$ Online Published: August 3, 2012

doi:10.5539/jedp.v2n2p32

URL: http://dx.doi.org/10.5539/jedp.v2n2p32

\begin{abstract}
This study examined (a) the relation between children's participation in organized leisure activities (OLA) during kindergarten and social competence in Grade 1 and (b) whether this relation would vary according to families' income level. Participants were 556 preschool children ( $59 \%$ boys; $M$ age $=5.65$ years). Measures were obtained from parents and teachers who completed a series of questionnaires about the child. Social competence was assessed using measures of social skills and externalized behaviour. Results suggested that children who participated in OLA in kindergarten showed significantly enhanced social skills in Grade 1 than those who did not participate, and this link was true regardless of income level. In addition, results revealed that OLA participation in kindergarten significantly predicted a decrease in externalized behaviour in Grade 1 only among low-income children. The theoretical and practical implications of the results are discussed.
\end{abstract}

Keywords: preschool children, social competence, organized leisure activities

\section{Introduction}

Leisure time represents a large part of children's lives (Vandell \& Shumow, 1999). Several children are involved in a range of organized activities, such as competitive sports teams, music organizations or intellectual oriented activities (e.g., chess lessons, science clubs) during this leisure time. The current study examines the contribution of participation in these activities on the emergence of social competence among preschoolers. Very few studies have been conducted so far on participation in organized activities during this developmental period, even though theoriticians have emphasized the importance of considering the influence of every context in a child's social life (Bronfenbrenner, 1977, 1986).

\subsection{Development of Social Competence in Early Childhood}

When children enter kindergarten, interpersonal relationships play a predominant role in their lives (Hartup, 1989, 1996). Hartup has suggested that a child's social competence emerges from experience drawn in close relationships. Indeed, social competence reflects the child's effectiveness in dealing with everyday social situations. Two components are essential for the child to be able to behave in socially appropriate manners with other children and adults. First, social competence requires the presence of a basic set of social skills as well as the ability to implement them when initiating and maintaining interpersonal relationships. Second, social competence implies acceptance and positive regard from others and is therefore related to social adjustment as reflected in the behaviour a child exhibits in social situation (Fantuzzo, Collahan, \& Mendez, 1998, Hartup, 1989).

According to Hartup's perspective $(1989,1996)$, two types of social experience are crucial for the emergence of social competence in children: vertical and horizontal relationships. A vertical relationship refers to an attachment to an individual who have greater knowledge and social power than the child does (usually an adult). Such relationship often revolves around the child's nurture and education. For instance, parents have the responsibility to take care of their young children's basic needs and to teach them essential social skills. As children get older, basic needs continue to be fulfilled by their parents, but other adults can also be involved when children spend time in social activities. Hence, vertical relationships in early childhood contribute to teach basic social skills to young children.

In contrast, horizontal relationships are marked by equal knowledge and social power. These relationships 
include friendships with peers which are largely based on reciprocity and egalitarian exchanges. Thus, horizontal relationships provide children with rich opportunities to practice and elaborate social skills learned within vertical relationships. By interacting with mates similar to themselves, children learn to master complex skills (e.g., cooperation, intimacy) in social relations (Hartup, 1989).

Consequently, vertical and horizontal relationships serve distinct functions in children's development of social skills. Moreover, it is believed that the quality of these two kinds of relationships may contribute to children's social adjustment. Indeed, adults within vertical relationships often represent attachment figures to children. Accordingly, these vertical relationships may be reproduced by children and serve as models for future relationships (Bowlby, 1973). Similarly, horizontal relationships may affect children's social adjustment in two ways. First, children may learn social behaviours by imitating their peers' behaviour or by submitting to peer pressure (Hartup, 2005). Second, as the child experiments with his newly acquired social skills, the ensuing result can lead to good or poor social adjustment.

Hartup's model $(1989,1996)$ asserts that the underlying structure found in social relationships and in activity settings plays a crucial role in the development of social competence. During the preschool years, children gain more autonomy and their opportunities thus increase greatly (Maccoby, 1984). Nevertheless, they still need a high amount of structure and supervision provided by a significant adult as a basis for support and validation of their judgment and actions (Buhrmester, 1992; Ladd \& LeSieur, 1996). Children also need structure in order to interpret and organize the results of their experiences with others. Moreover, it has been shown that a high level of structure in children's activities is associated with behavioural adjustment and academic performance (Marshall, Coll, Marx, McCartney, Keefe, \& Ruh, 1997; Pettit, Laird, Bates, \& Dodge, 1997), as well as social competence (Lieberman, Doyle \& Markiewics, 1999). Thus, the role of structure in activities appears to be significant for social development. Organized leisure activities allow building both vertical and horizontal relationships and offer high structure in the settings. Therefore, the pursuit of such activities may have a positive impact on the development of social competence in early childhood.

\subsection{Definition and Characteristics of Organized Leisure Activities}

National studies investigating time use by children have failed to distinguish the different levels of structure found in leisure activities (Fletcher, Nickerson, \& Wright, 2003; Vandell \& Shumow, 1999). Yet, the importance of this distinction has been widely recognized in the literature (Eccles \& Barber, 1999; Larson, 2000; Mahoney \& Stattin, 2000; Meeks \& Mauldin, 1990). Unstructured activities are ones in which children engage in spontaneously in order to occupy themselves and have fun (e.g., watching television, playing soccer with friends or hanging out). Ordinarily, these activities are recreational in nature and take place at home or in an after-school program. An adult may be nearby to provide some supervision, but is not directly involved in the activity.

Conversely, organised leisure activities (OLA) are highly structured and supervised. Structure is defined by: (a) the supervision, leadership and feedback of a significant adult, (b) the existence of formal rules and a particular setting, and (c) regular participation schedules (Larson, 2000; Mahoney \& Stattin, 2000). Fletcher et al. (2003) further added that a precise goal or objective must be present when defining OLA. Examples of OLA include competitive individual or team sports, art or academia related lessons or Sunday school. A study by Mahoney and Stattin (2000) has shown the importance of high structure in OLA for positive adjustment. In the current study, the characteristics described above were used as criteria for defining OLA participation.

\subsection{Impacts of Participation in Organized Leisure Activities}

Previous studies have consistently demonstrated that OLA participation promotes positive adjustment in adolescence. Social understanding and competence, academic success (Larson, 2000; Mahoney, Larson, \& Eccles, 2005), low levels of antisocial behaviour (Mahoney, 2000; Mahoney \& Stattin, 2000), low levels of depressive symptoms (Mahoney, Schweder, \& Stattin, 2002) and low rate of school drop-out (Mahoney \& Cairns, 1997; McNeal, 1995) were all found to be associated with OLA involvement.

Positive outcomes among school-age children have also been documented. OLA participation has been linked to higher academic achievement, psychosocial maturity, social competence and self-esteem as reported by parents and teachers (Fletcher et al., 2003; McHale, Crouter, \& Tucker, 2001). The long term effects of OLA participation on adjustment has also been suggested in the literature. Findings revealed that children with behavioural problems who were involved in OLA were less likely to drop out of school in adolescence and to be arrested in the beginning of adulthood compared to those who were not involved (Mahoney, 2000; Mahoney \& Cairns, 1997).

Larson (2000) and Mahoney (2000) pointed out that a selection bias could explain the association between OLA 
participation and positive outcomes. These investigators suggested that because of its voluntary nature, certain characteristics in children could be linked to participation, which would then lead to positive outcomes. For exemple, among young children, decision to participate in OLA is often made by parents who take into account their child's characteristics (Ladd \& LeSieur, 1996). As such, they may consider their child's social skills or competence. Therefore, one way to partially control for the potential selection effect is to use a longitudinal design in which children's initial characteristics would be taken into account (Mahoney, 2000; Mahoney \& Cairns, 1997).

\subsection{OLA Participation and Social Competence in Preschool}

As mentioned above, OLA participation appears to be positively associated with indicators of social competence and adjustment in middle childhood and adolescence. However, hardly any studies to our knowledge have described the impact of OLA participation in early childhood at the very beginning of the school curriculum. Since evidence shows that the benefits of participation are not age-related (Fletcher et al., 2003), participation in OLA should have a positive impact on young children as well.

OLA may represent an optimal setting for the development of social competence among preschoolers. Indeed, OLA settings strongly encourage the emergence of positive vertical relationships. Establishing a relationship with a significant adult is often made easier and encouraged in an OLA setting (Mahoney \& Stattin, 2000). Moreover, the adult leader is responsible for helping the child foster the specific skills required for the activity and for peer interaction. Finally, the feedback given by the adult constitutes a form of modeling for other adult-child relationships (Larson \& Verma, 1999). Rich opportunities for horizontal relationships may also be provided in OLA settings. More than one child usually participates in the same OLA which creates interactions among peers who share similar interests and goals. Furthermore, in order to reach a common goal, children must exercise their social skills and engage in positive interactions with their peers in order to succeed in the activity (Eccles \& Barber, 1999; Kleiber, Larson, \& Csikszentmihalyi, 1986; Larson, 1994; McHale et al., 2001).

Taken as a whole, OLA provides numerous positive opportunities to engage in vertical and horizontal relationships within a highly structured setting. In light of Hartup's model $(1989,1996)$, one can therefore expect that young children who participate in OLA would have more opportunities to develop their social competence. In this study, two dimensions of social competence were considered, i.e., social skills and low levels of externalized behaviour. Specifically, it was hypothesized that participation in OLA during kindergarten would promote social competence (i.e., increased social skills and low levels of externalized behaviour) in first grade than non-participation.

Additionally, it should be noted that youths who come from low SES families usually benefit more from structured activities and after-school programs (Marshall et al., 1997; Pettit et al., 1997; Posner \& Vandell, 1994, 1999). This has been shown to be true for children attending kindergarten and elementary school (Posner \& Vandell, 1994, 1999) as well as for adolescents coming from low income families (Mahoney, 2000; Mahoney \& Stattin, 2000). Vandell and Shumow (1999) proposed that children from low income families may benefit more from these programs than children who come from moderate or high SES because such programs may compensate for lacks of care and education at home. As a result, it was hypothesized that preschoolers from low income families who participate in OLA would experience more benefits in their social competence (i.e., increased social skills and low levels of externalized behaviour) compared to children from moderate or high income families who also participate in OLA.

\section{Method}

\subsection{Participants}

Participants in the current study were recruited in the context of a larger research project assessing the impact of a conduct disorder prevention program. First of all, a sample of preschoolers exhibiting high levels of behaviour problems was initially screened (typically one children per classroom) and exposed to the targeted prevention program. Second, a group of preschoolers randomly chosen among the other children of the classrooms were recruited in order to establish measurement norms for the assessment battery. These children therefore participated in all the assessment but were not involved in any intervention. They formed the final sample in the current study and were from 173 kindergarten classrooms in 40 schools. Written parental consent was obtained for each student.

The final sample consisted of children for whom complete data were available in kindergarten and in first grade. This sample consisted of 556 children ( $59 \%$ boys; mean age $=5.65$ years). Data were not available in first grade for 173 children, mainly because they transitioned into elementary schools that were not involved in our research 
projects. The children in this sample came from predominantly middle-class families (median household income $=60000 \$-79000 \$$ ).

\subsection{Procedure}

Data were collected in the fall of kindergarten and in the fall of Grade 1. Teachers' and parents' questionnaires were brought to the schools by research assistants. Teachers were then instructed to pass on parents' questionnaire through the child. Next, parents were asked to return the completed questionnaire to the teacher in a sealed envelope. Approximately two weeks after, research assistants returned to the schools in order to bring back the questionnaires completed by teachers and parents.

\subsection{Measures}

\subsubsection{Participation in Organized Leisure Activities}

Mothers were asked to report all the OLA in which their child participated in during kindergarten. In order to be considered as an OLA, activities had to fit the following criteria: (a) presence of an adult leader, (b) precise rules and particular setting, (c) regular schedules and (d) specific goals or objectives. Children were then assigned a score of 0 if they did not participate in any OLA and a score of 1 if they participated in at least one OLA. It should be noted that $60.9 \%$ of children participated in at least one OLA. The mean number of activities for those who participated was 1.68 and the most frequent activities were ice hockey, soccer and music lessons.

\subsubsection{Social Skills}

Social skills were measured using an abbreviated version of the Social Skills Rating System developed by Gresham and Elliot (1990). Teachers rated the frequency of 19 behaviours pertaining to social skills using a 3 -point Likert scale $(0=$ never, $1=$ seldom, $2=$ often $)$. Three dimensions were assessed: assertiveness, cooperation and self-sontrol. The mean of all 19 items was used as a global score indicating social skills. Adequate internal consistency was found (Cronbach alpha $=.88$ both in kindergarten and first grade).

\subsubsection{Externalized Behaviour}

Externalized behaviour was assessed using a 35-item questionnaire covering a range of behaviours: reactive/proactive aggression, physical/indirect aggression, opposition, conduct problems, attention deficit and hyperactivity. The items were selected from different instruments (Crick et al., 1999; Dodge \& Coie, 1987; Tremblay, Desmarais-Gervais, Gagnon, \& Charlebois, 1987). Teachers rated the frequency at which the child displayed each behaviour in the last month using a 6-point Likert scale $(1=$ never and $6=$ often $)$. A mean score was computed using the 35 items. High internal consistency was found (Cronbach alpha $=.97$ both in kindergarten and first grade).

\subsubsection{Demographic Data}

Mothers reported their annual household income by referring to pre-determined response scale showing different income categories (10 point-scale; from "less than 20000 " to "more than 100000 ").

\section{Results}

\subsection{Correlations among the Study Variables}

Descriptive statistics including the means, the respective standard deviations along with the correlations among all variables are presented in Table 1. Participation was positively associated with income and social skills (in kindergarten and Grade 1), and negatively associated with externalized behaviour in Grade 1. In addition, social skills (in both kindergarten and Grade 1) were negatively correlated with gender and positively associated with income. Finally, externalized behaviour (in both kindergarten and Grade 1) was positively associated with gender, negatively associated with income, and negatively associated with social skills in both years. Overall, outcomes were strongly correlated amongst each other, suggesting that they assessed related construct. Moreover, outcomes measured in kindergarten were strongly correlated to themselves when measured in first grade, suggesting relative stability in the constructs. 
Table 1. Means, standard deviations, and correlations among the study variables

\begin{tabular}{|c|c|c|c|c|c|c|c|c|c|}
\hline Variables & 1 & 2 & 3 & 4 & 5 & 6 & 7 & $M$ & $S D$ \\
\hline 1. Gender & 1 & - & - & - & - & - & - & - & - \\
\hline 2. Income & -.00 & 1 & - & - & - & - & - & 5.57 & 2.47 \\
\hline 3. Participation & .02 & $.29 * * *$ & 1 & - & - & - & - & 0.53 & 0.50 \\
\hline 4. Social skills (K) & $-.18^{* * *}$ & $.14 * * *$ & $.11^{* *}$ & 1 & - & - & - & 1.43 & 0.32 \\
\hline 5. Social skills (G1) & $-.20^{* * *}$ & $.17 * * *$ & $.12 * *$ & $.44 * * *$ & 1 & - & - & 1.42 & 0.34 \\
\hline 6. Externalizing (K) & $.13 * * *$ & $-.18^{* * *}$ & -.05 & $-.56 * * *$ & $-.42 * * *$ & 1 & - & 1.82 & 0.77 \\
\hline 7. Externalizing (G1) & $.21 * * *$ & $-.19 * * *$ & $-.09 *$ & $-.46 * * *$ & $-.61 * * *$ & $.58 * * *$ & 1 & 1.74 & 0.76 \\
\hline
\end{tabular}

Note. $\mathrm{K}=$ Kindergarten; $\mathrm{G} 1=$ Grade $1 .{ }^{*} p<.05 .{ }^{*} p<.01 . * * * p<.001$.

\subsection{Predictions to Outcome Variables}

There were two main goals in the current investigation. The first one was to determine if OLA participation in kindergarten had a significant effect on social skills and externalized behaviour in first grade. The second goal was to determine if this effect was greater for children of low income household, thus determining whether income was a moderator. Analyses were conducted in two steps. First, hierarchical linear regressions were used to test the effect of OLA participation on social skills and externalized behaviour. Moreover, gender and initial outcome variables obtained in kindergarten were included as control variables because they were shown to be strongly correlated to outcome variables in Grade 1. Therefore, by including these control variables in the models, we were able to isolate the effect of participation on social skills and externalized behaviour. Second, the moderating effect of income was examined by introducing a Participation $\mathrm{X}$ Income interaction term in the regression model according to Baron and Kenny's procedure (1986).

\subsubsection{Social Skills}

A first hierarchical linear regression analysis was conducted to examine the relation between OLA participation in kindergarten and social skills in Grade 1, with participants' social skills as dependent variable and with income as a moderator. On the first step of the analysis, participants' gender and initial level of social skills in kindergarten were included as control variables. On the second step, participation and income were entered as predictors in the model. To facilitate interpretation, the income variable was $z$-standardized for the creation of the interaction term Participation X Income which was added on the third step. As can be seen in Table 2, the results of the second step indicated that, after controlling for participants' gender and initial level of social skills in kindergarten, participation and income together explained $24 \%$ of the variance of social skills in Grade $1\left[\mathrm{R}^{2}\right.$ adj $=.23, F(2,459)=5.22, p<.01]$. Inspection of the partial regression coefficients revealed a main effect of participation on social skills, $b=.03, p<.05$, whereas the main effect of income on social skills was not significant, $b=.01, n s$. Further, the interaction term entered on the third step did not add to explain the overall variance of social skills. Taken together, results indicated that OLA participation in kindergarten significantly predicted an increase in participants' social skills in Grade 1, but this link did not differ as a function of children's level of income.

Table 2. Hierarchical linear regression analysis predicting to social skills at grade 1

\begin{tabular}{clllll}
\hline & Predictor & $b$ & $t$ & $F$ change $(d f)$ & $R^{2}$ change \\
\hline Step 1 & & & & $64.34(2,461)$ & $.22^{* * *}$ \\
& Gender & -.11 & $-3.68 * * *$ & & \\
& Social Skills K & .46 & $9.80 * * *$ & & $.02 * *$ \\
Step 2 & & & & $5.22(2,459)$ & .00 \\
& Participation & .03 & $2.16^{*}$ & & $.00(1,458)$ \\
Step 3 & Income & .01 & 1.78 & & \\
& & & &
\end{tabular}




\subsubsection{Externalized Behaviour}

A similar hierarchical linear regression analysis was performed to examine the relation between OLA participation in kindergarten and externalized behaviour in Grade 1, with participants' externalized behaviour as dependent variable and with income as a moderator. As can be seen in Table 3, the results of the second step indicated that, after controlling for participants' gender and initial level of externalized behaviour in kindergarten, participation and income together explained $37 \%$ of the variance of social skills in Grade $1\left[\mathrm{R}^{2}\right.$ adj $=.36, F(2$, $470)=4.04, p<.05]$. Inspection of the partial regression coefficients revealed a main effect of income on externalized behaviour, $b=-.02, p<.05$, whereas the main effect of participation on externalized behaviour was not significant, $b=-.02$, ns. Further, the interaction term entered on the third step explained an additional $1 \%$ of the overall variance of externalized behaviour $\left[\mathrm{R}^{2}\right.$ change adj $=.01, F$ change $\left.(1,469)=5.21, p<.05\right]$.

To break down the interaction, the link between participation and externalized behaviour was examined when children's level of income was at the mean (i.e., $=0$ on the $z$-standardized measure of income), $1 \mathrm{SD}$ above the mean, and 1 SD below the mean. The effect of participation on externalized behaviour at an average level of income was already given on the second step of the previous regression analyses, $b=-.02, n s$. When income was $1 \mathrm{SD}$ below the mean, participation was significantly related to externalized behaviour, $b=-.09, p<.05$. Finally, when income was $1 \mathrm{SD}$ above the mean, participation was not significantly related to externalized behaviour, $b$ $=.05, n s$. As such, the results indicate that children who participate in OLA showed less externalized behaviour subsequently, but this pattern was significant only for children whose income was low.

Table 3. Hierarchical linear regression analysis predicting to externalized behaviour at grade 1

\begin{tabular}{|c|c|c|c|c|c|}
\hline & Predictor & $\bar{b}$ & $t$ & $F$ change $(d f)$ & $R^{2}$ change \\
\hline \multirow[t]{3}{*}{ Step 1} & & & & $131.72(2,472)$ & $.36^{* * *}$ \\
\hline & Gender & .25 & $4.28 * * *$ & & \\
\hline & Extern. behaviour K & .56 & $14.96 * * *$ & & \\
\hline \multirow[t]{3}{*}{ Step 2} & & & & $4.04(2,470)$ & $.01 *$ \\
\hline & Participation & -.03 & -.96 & & \\
\hline & Income & -.03 & $-2.36^{*}$ & & \\
\hline \multirow[t]{2}{*}{ Step 3} & & & & $5.21(1,469)$ & $.01 *$ \\
\hline & Participation X Income & -.07 & $2.28 *$ & & \\
\hline
\end{tabular}

Note. Extern. $=$ Externalized; $\mathrm{K}=$ Kindergarten. $n=475 . * p<.05 . * * * p<.001$.

\section{Discussion}

The transition from kindergarten to elementary school is a crucial period during which both vertical and horizontal relationships are necessary for the development of social competence. Since OLA provides a setting for experiencing both types of relationships, participation in OLA was expected to have a positive effect on social competence, particularly among preschoolers from low SES. Results showed that participation in at least one OLA had an effect on the two main components of social competence: social skills and externalized behaviours.

\subsection{OLA Participation and Social Skills}

OLA participation was positively associated with social skills. This suggests that participation may indeed be beneficial for the acquisition of social skills among young children. Several interpretations could be made to explain this finding. First, the presence of an adult leader in OLA settings possibly allows children to engage in a rewarding vertical relationship (Hartup, 1989). Certainly, other adult-child relationships (e.g., parents, relatives, and teachers) are likely to be present in children's lives. However, children who participate in OLA have one additional opportunity for interacting in a vertical relationship. Supporting this idea, we found that OLA participation had a significant positive effect on children's social skills, despite the fact that all children in this study had at least one parent and school teacher in their lives. Unique characteristics of the adult leader may also contribute to children's social skills development. For instance, the nature of feedbacks given by the activity adult may differ from those given by parents and teachers. As such, the adult leader may provide clearer and more immediate feedback and reinforcement to the child (Csikszentmihalyi, 1990). In sum, the current study 
lends credence to the strong role of the adult leader in OLA settings for children's social development.

Second, results of the current study suggest that OLA constitute fertile grounds for building horizontal relationships. Children who participate in OLA have greater opportunities to form relationships with other peers present during the activity (Mahoney \& Stattin, 2000). Moreover, OLA provides unique and effective contexts for practicing social skills. Indeed, children must obey rules and work jointly with peers in order to achieve a common goal, thereby emphasizing structure and direction toward skill development (Mahoney \& Stattin, 2000). Finally, it should be reminded that OLA are voluntary in nature and are usually held in a pleasant atmosphere. This may contribute to maintain children's motivation and enjoyment for the activity and generate more significant bonding and learning experiences (Cordova \& Lepper, 1996).

\subsection{OLA Participation and Externalized Behaviour}

Results showed that OLA participation was associated with a decrease in externalized behaviour and this link was moderated by income level. In other words, only children from low income level who participated in OLA in kindergarten showed a significant reduction in externalized behaviour one year later. This finding converges with other studies showing that unsupervised activities predict poorer behavioural adjustment and that this association is stronger for lower-income youths (Marshall et al., 1997; Pettit et al., 1997). One interpretation is that the vertical relationships fostered in OLA settings may play a more active and supportive role for children from low SES. It has been shown that youths who are involved in OLA perceive higher social support from their activity leaders compared with youths who are involved in unstructured activities (Mahoney \& Stattin, 2000). Further, research has indicated that "difficult" children are more susceptible to environmental effects (Belsky, 1997), which may explain why the effects of structured programs are found to be greater for children who have substantial behavioural problems than for children who have few behaviour problems (Vandell et al., 2005). Thus, it may be that the high amount of structure in OLA settings compensate for deficits in other areas of children's lives (e.g., poor quality parenting strategies, poor academic competence).

A final interpretation is that social contact with other peers who exhibit low externalized behaviour may be beneficial for low-income children. Several reviews have demonstrated that the characteristics of peers featured in OLA settings are important. In other words, with whom children engage in an activity may be as important as what the activity consists of (Mahoney \& Stattin, 2000). In this regard, it has been reported that the social context of OLA includes peers who are socially competent and prosocial (Mahoney \& Stattin, 2000). Therefore, by spending their free time in OLA, low-income children experience greater opportunity to interact in horizontal relationships with well-adjusted and non-deviant peers. These peers may compensate for the lack of adequate models in the lives of low-income children and the nature of their influence is likely to be positive for children's social development.

The current findings indicate that participation in OLA is beneficial in early childhood. Because enhanced social competence leads to improved adjustment, OLA participation should clearly be encouraged among preschoolers. One implication is to facilitate access to these types of activities by promoting knowledge and interest in OLA, increasing their availability and diminishing their elevated costs. More importantly, special consideration and easier access should be granted to children from lower income. In this respect, evidence shows that they are the ones who would benefit more from OLA, but they are also the ones who participate less. Finally, participation in OLA should be considered a useful tool for promoting social competence and should not be used as a replacement for intervention programs targetting children with social and behavioural difficulties.

\subsection{Limitations and Future Directions}

Taken together, the current study supports Hartup's $(1989,1996)$ model of social competence as the possible mecanism by which OLA affects children's social development. However, it should be reminded that vertical and horizontal relationships were not actually measured neither quantitatively nor qualitatively in the present investigation. As such, the model offers an explanation of the processes in place, but further studies are clearly needed to explain how these two kinds of relationships contribute to OLA participation. In addition, the present study is preliminary and shows a positive association between OLA involvement and only two measures of social adjustment (i.e., social skills and externalized behaviour). Other measures of adjusment including internalized behavior, self-esteem and academic achievement should be included in future studies. Moreover, other interpersonal contexts, such as parent-child relationships, that are likely to contribute to development of social competence should be considered in future research. Even though the sample was large and representative, the correlationnal design of the study cannot ascertain the direction of causality between OLA participation and adjustment outcomes. It would be interesting to assess the long term effects of OLA participation in future work. New studies should also consider other aspects of OLA participation, such as duration, time spent engaging in 
the activity, number of participants, number of adults present, number and type of activity. For instance, one can wonder whether a large number of activities imposed by the parents would cancel the beneficial effects of OLA or even have a detrimental impact on children's well-being. In sum, the study of these different characteristics is likely to contribute greatly to an understanding of the underlying mechanism by which structured activities benefit participating children.

\section{Acknowledgements}

This study was supported by research grants from the Social Sciences and Humanities Research Council of Canada, the Fonds Québécois pour la Recherché sur la Société et la Culture and the Canadian Institutes for Health Research. The authors wish to thank the teachers and children of the Commission scolaire de Laval.

\section{References}

Baron, R., \& Kenny, D. (1986). The moderator-mediator variable distinction in social psychological research: conceptual, strategic, and statistical considerations. Journal of Personality and Social Psychology, 51, 1173-1182. http://dx.doi.org/10.1037/0022-3514.51.6.1173

Belsky, J. (1997). Variation in susceptibility to environmental influence: An evolutionary argument. Psychological Inquiry, 8, 182-186. http://dx.doi.org/10.1207/s15327965pli0803_3

Bowlby (1973). Attachment and loss: Separation (Vol. 2). New York: Basic Books.

Bronfenbrenner, U. (1977). Toward an experimental ecology of human development. American Psychologist, 32, 513-531. http://dx.doi.org/10.1037/0003-066X.32.7.513

Bronfenbrenner, U. (1986). Ecology of the family as a context for human development: Research perspectives. Developmental Psychology, 22, 723-742. http://dx.doi.org/10.1037/0012-1649.22.6.723

Buhrmester, D. (1992). The developmental courses of sibling and peer relationships. In F. Boer \& J. Dunn (Eds.), Children's sibling relationships: Developmental and clinical issues (pp. 19-40). Hillsdale, NJ, England: Lawrence Erlbaum Associates, Inc.

Cordova, D. I., \& Lepper, M. R. (1996). Intrinsic motivation and the process of learning: Beneficial effects of contextualization, personalization, and choice. Journal of Educational Psychology, 88, 715-730. http://dx.doi.org/10.1037/0022-0663.88.4.715

Crick, N., Werner, N., Casas, J. F., O'Brien, K. M., Nelson, D. A., Grotpeter, J. K., \& Markon, K. (1999). Childhood aggression and gender: A new look at an old problem. In D. Bernstein (Eds.), Gender and motivation (pp. 75-141). Lincoln, NE: University of Nebraska Press.

Csikszentmihalyi, M. (1990). Flow: The Psychology of Optimal Experience. New York: Harper \& Row.

Dodge, K. A., \& Coie, J. D. (1987). Social-information-processing factors in reactive and proactive aggression in children's peer groups. Journal of Personality and Social Psychology. Special Issue: Integrating personality and social psychology, 53, 1146-1158.

Eccles, J. S., \& Barber, B. L. (1999). Student council, volunteering, basketball, or marching band: What kind of extracurricular involvement matters? Journal of Adolescent Research, 14, 10-43. http://dx.doi.org/10.1177/0743558499141003

Fantuzzo, J., Coolahan, K., Mendez, J., McDermott, P., \& Sutton-Smith, B. (1998). Contextually-relevant validation of peer play constructs with African American Head Start children: Penn Interactive Peer Play Scale. Early Childhood Research Quarterly, 13, 411-431. http://dx.doi.org/10.1016/S0885-2006(99)80048-9

Fletcher, A. C., Nickerson, P., \& Wright, K. L. (2003). Structured leisure activities in middle childhood: Links to well-being. Journal of Community Psychology, 31, 641-659. http://dx.doi.org/10.1002/jcop.10075

Gresham, F., \& Elliott, S. (1990). Social Skills Rating System. Cirle Pines, MN: American Guidance Service, Inc.

Hartup, W. W. (1989). Social relationships and their developmental significance. American Psychologist, 44, 120-126. http://dx.doi.org/10.1037/0003-066X.44.2.120

Hartup, W. W. (1996). The company they keep: Friendships and their developmental significance. Child Development, 67, 1-13. http://dx.doi.org/10.2307/1131681

Hartup, W. W. (2005). Peer interaction: What causes what? Journal of Abnormal Child Psychology, 33, 387-394. http://dx.doi.org/10.1007/s10802-005-3578-0 
Kleiber, D., Larson, R., \& Csikszentmihalyi, M. (1986). The experience of leisure in adolescence. Journal of Leisure Research, 18, 169-176.

Ladd, G., \& Le Sieur, K. (1995). Parents and children's peer relationships. Handbook of parenting, 4, 377-409.

Larson, R. W. (2000). Toward a psychology of positive youth development. American Psychologist, 55, 170-183. http://dx.doi.org/10.1037/0003-066X.55.1.170

Larson, R. W., \& Verma S. (1999). How children and adolescents spend time across the world: Work, play, and $\begin{array}{lllll}\text { developmental } & \text { opportunities. } & \text { Psychological } & \text { Bulletin, } & 125,\end{array}$ http://dx.doi.org/10.1037/0033-2909.125.6.701

Lieberman, M., Doyle, A-B, Markiewicz, D. (1999). Developmental patterns in security of attachment to mother and father in late childhood and early adolescence: Associations with peer relations. Child Development, 70, 202-213. http://dx.doi.org/10.1111/1467-8624.00015

Maccoby, E. E. (1984). Socialization and developmental change. Child Development, 55, 317-328. http://dx.doi.org/10.2307/1129945

Mahoney, J. L. (2000). School extracurricular activity participation as a moderator in the development of antisocial patterns. Child Development, 71, 502-516. http://dx.doi.org/10.1111/1467-8624.00160

Mahoney, J. L., \& Cairns, R. B. (1997). Do extracurricular activities protect against early school dropout? Developmental Psychology, 33, 241-253. http://dx.doi.org/10.1037/0012-1649.33.2.241

Mahoney, J. L., Cairns, B. D., \& Farmer, T. W. (2003). Promoting interpersonal competence and educational success through extracurricular activity participation. Journal of Educational Psychology, 95, 409-418. http://dx.doi.org/10.1037/0022-0663.95.2.409

Mahoney, J. L., Larson, R. W., \& Eccles, J. S. (Eds.) (2005). Organized activities as contexts of development: Extracurricular activities, after-school, and community programs. Mahwah, NJ: Erlbaum.

Mahoney, J. L., Schweder, A. E., \& Stattin, H. (2002). Structured after-school activities as a moderator of depressed mood for adolescents with detached relations to their parents. Journal of Community Psychology, 30, 69-86. http://dx.doi.org/10.1002/jcop.1051

Mahoney, J. L., \& Stattin, H. (2000). Leisure activities and adolescent antisocial behaviour: The role of structure and social context. Journal of Adolescence, 23, 113-127. http://dx.doi.org/10.1006/jado.2000.0302

Marshall, N. L., Coll, C. G., Marx, F., McCartney, K., Keefe, N., \& Ruh, J. (1997). After-school time and children's behavioral adjustment. Merrill-Palmer Quarterly, 43, 497-514.

McHale, S. M., Crouter, A. C., \& Tucker, C. J. (2001). Free-time activities in middle childhood: Links with adjustment in early adolescence. Child Development, 72, 1764-1778. http://dx.doi.org/10.1111/1467-8624.00377

McNeal, R. B. (1995). Extracurricular activities and high school dropouts. Sociology of Education, 68, 62-81. http://dx.doi.org/10.2307/2112764

McNeal, R. B. (1998). High school extracurricular activities: Closed structures and stratifying patterns of

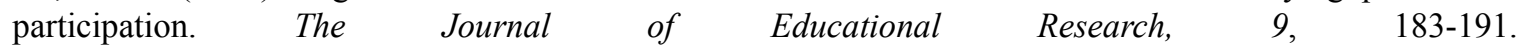
http://dx.doi.org/10.1080/00220679809597539

Meeks, C. B., \& Mauldin, T. (1990). Children's time in structured and unstructured leisure activities. Lifestyles, 11, 257-281. http://dx.doi.org/10.1007/BF00987003

Pettit, G. S., Laird, R. D., Bates, J. E., \& Dodge, K. A. (1997). Patterns of after-school care in middle childhood: Risk factors and developmental outcomes. Merrill-Palmer Quarterly, 43, 515-538.

Pierce, K. M., Hamm, J. V., \& Vandell, D. L. (1999). Experiences in after-school programs and children's $\begin{array}{llll}\text { adjustment in first-grade classrooms. Child Development, } & \text { 70, }\end{array}$ http://dx.doi.org/10.1111/1467-8624.00054

Posner, J. K., \& Vandell, D. L. (1994). Low-income children's after-school care: Are there beneficial effects of after-school programs? Child Development. Special Issue: Children and poverty, 65, 440-456.

Posner, J. K., \& Vandell, D. L. (1999). After-school activities and the development of low-income urban children: $\begin{array}{lllll}\text { A longitudinal study. Developmental } & \text { Psychology, } & 35, & 868-879 .\end{array}$ http://dx.doi.org/10.1037/0012-1649.35.3.868 
Schneider, B. H. (1993). Children's social competence in context: The contributions of family, school and culture. Elmsford, NY: Pergamon Press.

Tremblay, R. E., Desmarais-Gervais, L., Gagnon, C., \& Charlebois, P. (1987). The Preschool Behaviour Questionnaire: Stability of its factor structure between cultures, sexes, ages and socioeconomic classes. International Journal of Behavioral Development, 10, 467-484.

Vandell, D. L., \& Shumow, L. (1999). After-school child care programs. The Future of Children, 9, 64-80. http://dx.doi.org/10.2307/1602707

Vandell, D. L., Shumow, L., \& Posner, J. (2005). After-school programs for low-income children: Differences in program quality. In J. L. Mahoney, R. W. Larson \& J. S. Eccles (Eds.), Organized activities as contexts of development: Extracurricular activities, after-school and community programs (pp. 437-456). Mahwah, NJ: Lawrence Erlbaum Associates Publishers. 